CRÍTICA, Revista Hispanoamericana de Filosofía

Vol. XXX, No. 88 (abril 1998): 3-28

\title{
THE THEORY OF MEANING AND THE PRACTICE OF COMMUNICATION
}

BARRY STROUD

University of California

Berkeley

Near the end of his essay "A Nice Derangement of Epitaphs" Donald Davidson, writing in English, concludes that "there is no such thing as a language". Some people have stopped reading at that point. But that is not all he wrote - even in that very sentence. What he says is: "there is no such thing as a language, not if a language is anything like what many philosophers and linguists have supposed". ${ }^{1}$ I take this as my text. I want to explore what I think Davidson is getting at here. I find it very important - and something that a great many philosophers continue to miss, or even to deny.

To explain what he means by saying that a language is nothing like what many philosophers and linguists have supposed we have to ask what they have supposed. Those Davidson has in mind have supposed that, as he puts it, "communication by speech requires that speaker and interpreter have learned or somehow acquired a common

${ }^{1}$ D. Davidson, "A Nice Derangement of Epitaphs", in R. Grandy and R. Warner (eds.), Philosophical Grounds of Rationality: Intentions, Categories, Ends, Oxford University Press, Oxford, 1986, p. 174. 
method or theory of interpretation - as being able (sic) to operate on the basis of shared conventions, rules, or regularities". ${ }^{2}$ He thinks that supposition must be wrong, because "no method or theory fills this bill". ${ }^{3}$ If communication by speech required such a method or theory, there would be no such thing as communication by speech.

So when he denies that there is such a thing as a language as many philosophers and linguists have thought of it what he is denying is that there is such a thing as "linguistic competence as often described". " The main culprit in descriptions of linguistic competence is again an assumption that he puts this way: "The systematic knowledge or competence of the speaker or interpreter is learned in advance of occasions of interpretation and is conventional in character." 5 That is what he thinks has to go. It is an idea he argued against in his paper "Communication and Convention" as well. " "We must give up the idea of a clearly defined shared structure which language-users acquire and then apply to cases", 7 he says. In short, "we should give up the attempt to illuminate how we communicate by appeal to conventions". 8

Now what exactly is being denied here - and so what is being positively said or implied about how we do communicate? There is no question that people communicate by speech; many people are very good at it. But there also seems to be no question that those who are good at it

2 Ibid.

3 Ibid.

${ }^{4}$ Ibid.

${ }^{5}$ Ibid., p. 161.

${ }^{6}$ In his Inquiries Into Truth and Interpretation, Oxford University Press, Oxford, 1984.

7 “A Nice Derangement of Epitaphs", p. 174.

8 Ibid. 
are competent, even fluent, in some particular language. What is the bad way of thinking of that competence that Davidson is warning us against? Is it wrong to think that a person's competence in a particular language is, as he says, "learned or somehow acquired"? Surely not. Is it wrong to think of a person's competence as "learned or acquired in advance of occasions of interpretation"? Well, no. I acquired my competence in English in advance of the "occasions of interpretation" that I have been presented with in, say, the last ten years. I could speak English just as well ten years ago as I can now. And there will be, I hope, a great many "occasions of interpretation" yet to come, in my future. So my present competence has been acquired in advance of all of those occasions. But was my competence in English "learned or acquired in advance of" all "occasions of interpretation"? I don't think so. It was only because the people around me said things in English on certain "occasions of interpretation" in my surroundings, and because I had to catch on to what they were saying on those occasions, that I became competent in English. If no one had ever said anything in my presence, I probably would not have acquired any particular linguistic competence at all.

Is that something that many philosophers and linguists would deny? Some would say that an infant is born with a general capacity for language, perhaps even a "language module", in advance of exposure to the sounds of any particular language, and in that sense has a prior capacity to acquire particular languages by exposure. But does anyone hold that competence or fluency in English or Spanish or any other particular language is acquired in advance of all "occasions of interpretation"? Again, I don't think so.

What is more relevant to what I think Davidson is concerned with is to ask whether, as he puts it, a speaker's competence is "learned in advance of occasions of inter- 
pretation and is conventional in character". It is the idea that we can "illuminate how we communicate by appeal to conventions" that he thinks we have to get rid of - that we "operate on the basis of shared conventions, rules, or regularities".

What is the idea that we have to get rid of here? Is it the thought that speakers who communicate share certain rules or regularities in their speech, or that their speech conforms to certain shared conventions? I don't think that can be it. Speakers of English do communicate with one another, and I think they can also be said to follow certain rules or regularities in their speech. For instance, most English speakers on the whole follow the rule for pluralization: generally speaking, add ' $\mathrm{s}$ '. The rule for forming plurals is different in Italian. Of course, the rule I stated is only rough; there are many exceptions. But it is not that no precise rule can be formulated, in this or in any other case. Davidson does express doubts about whether all English speakers do follow the same rule for pluralization, ${ }^{9}$ but in general I don't think that in denying that we operate on the basis of shared conventions, rules, or regularities he means only that precise and exceptionless rules or regularities about English are not to be found. He does say that we must give up the idea of a "clearly defined shared structure which language-users acquire and then apply to cases", but I think the emphasis there is on a clearly-defined structure's not being shared and applied to cases, rather than on its not being shared and clearly defined.

After all, Davidson is the person who introduced, and who has done more than anyone else to promote, and to make vivid and promising, the idea of what he has called a systematic "theory of meaning" for a particular natural

${ }^{9}$ Ibid., p. 172. 
language - say, English. That theory would ideally take the form of a recursive theory of truth for that language, and would reveal the meanings of particular expressions by showing how a finite supply of elements can be put together to generate an indefinitely large number of new expressions with particular meanings by the application of a finite number of rules. That the correct meanings of English expressions can be generated in that way by those rules is to be shown by an empirical theory of English. So to be true, the theory and its rules must capture the way English speakers actually speak.

That is just what we would expect, since there is nothing else for a theory of meaning of a particular language to capture. What words or expressions mean in English can depend on nothing more than how those expressions are used by speakers of English. So the statements expressing the theory of meaning for English will be true only if English speakers actually speak in the ways they describe. The statements of the theory will be in that sense true generalizations - they will express what can be called regularities (and why not rules?) in the speech of English speakers. Of course, like most generalizations, they will be only approximately true, or true under a certain idealization. Many particular utterances by what are otherwise English speakers will deviate from them. But that does not mean that the structure that the theory ascribes to English is not "clearly defined". Nor does it mean, I think, that at a certain level of generality the regularities or rules are not shared. They are shared in the sense that the same regularities or rules are true of the speech of a great many people. It is only because that is so that they can be said to constitute of a theory of meaning for English.

I don't think Davidson denies, or has reason to deny, any of this. Surely he has not abandoned his central idea of an empirical theory of meaning for English. For the same 
reason I don't think he has reason to deny that there are shared conventions of English, given what I think he wants to stress about communication and linguistic competence. There might be to some extent simply a terminological difference here. I think there can be said to be a convention of, for instance, driving on the right in the United States and driving on the left in England. Of course, by now, it is required by law, but I don't think that means it is not conventional. If it is, then there are two different conventions in effect with respect to driving in two different Englishspeaking communities. Similarly, I think there is only one convention in effect in both those communities in English speakers' using the word 'and' to express conjunction, say, or in using the word 'bed' for something to sleep on, or in expressing the thought that snow is white by uttering the sentence 'Snow is white'. Spanish speakers have different conventional ways of doing those things. They share different conventions.

What I think Davidson does want to insist on about communication and linguistic competence is that, as he puts it, we do not "operate on the basis of shared conventions, rules, or regularities". That does not mean that there simply are no such things as conventions or rules, or that if there are they are not shared. The important idea is rather that whatever conventions, rules, or regularities there might be, they do not have the kind of role in communication that many philosophers and linguists have supposed. We do not "operate on the basis of" them.

Even if there is a clearly defined - or at least potentially definable - structure of a language that many speakers share, those language-users do not communicate with each other by taking that general structure and applying it to cases. Davidson will grant that we can think of a clearly defined theory of meaning for a language as a kind of machine which, when fed any arbitrary expression of 
the language, will grind out the meaning of that expression. But speaking and understanding what is said -in a word, communicating - is not just a matter of grinding out the meanings of expressions in that way. To think that an appeal to conventions or rules or theory can illuminate how we communicate is perhaps to suppose that it is. But communication involves more than the meanings of expressions. It is a matter of a person's saying something, and of one person's understanding what another person says.

That is what Davidson brings out by focussing first on malapropisms, mistakes, and misuses of words that nonetheless do not impede communication. When Mrs. Malaprop in Sheridan's play utters the words "a nice derangement of epitaphs" she is describing something as a nice arrangement of epigrams. That is what she means, and we know that that is what she means - just as we understand her when she describes someone as "the very pineapple of politeness" or says someone else is "as headstrong as an allegory on the banks of the Nile". Those are English words, but the meanings we rightly ascribe to her remarks are not the meanings that an empirical theory of meaning for English would grind out by applying to the words she utters the principles or rules of that theory. The theory would have her speaking of epitaphs, pineapples, and allegories, but we know better. The point is - and of course it does not depend on malapropisms - that we often understand what people say even when the words they use standardly mean something different from what we take the person to mean in uttering them on a particular occasion. If we have never heard those particular words used with those particular meanings before, we can still understand what is said. We can even understand someone when we have never heard any of his words used with any meanings at all before, and so have no idea what they mean. 
Two people do not have to share a language, or share the same words with the same meanings, in order to communicate successfully. So it is not true, as many philosophers and linguists have apparently supposed, that communication by speech requires that speaker and hearer share a common set of conventions, rules, or regularities. If they do not, they can still understand each other, but obviously they do not do so by the application of a clearly defined, or even loosely defined, theory of meaning for a language they share, or even a theory of meaning for one or another of the different languages that each of them happens to be master of.

Direct application of a theory of meaning for English would give the wrong answer in Mrs. Malaprop's case, even if we had such a theory and it was completely precise. It would be what Davidson calls a "standing" or "prior" theory: a general characterization of the meanings of expressions in the language which we might possess in advance of being presented with any "occasions of interpretation" from Mrs. Malaprop. When she speaks, we interpret her with what Davidson (somewhat oddly, to my ear) calls a "passing" theory: something that works at the moment for the particular utterance she has made. That is, we assign meanings to some of her words as used on that occasion which differ from the meanings assigned to those words by the standing or prior theory of English. But we do not assign those passing meanings to her words by applying to her utterances a general theory of meaning — even a passing theory of meaning. That is why speaking of a passing theory can be misleading. There is nothing more to having or employing what Davidson calls a passing theory of a person's utterance than interpreting or understanding that utterance - correctly identifying what the speaker is saying. That is a transient achievement; it says only what the speaker meant by certain words on that occasion. It 
has no predictive power. She might mean something completely different by those same words the next time. If she is Mrs. Malaprop, she probably will. But still, if we are good at understanding, we will be able to find out what she means the next time too.

We, as speakers and hearers and interpreters, understand what people are saying on particular occasions. We do so by identifying what they intend to say, even if they use their words in deviant ways or in ways that we are otherwise unfamiliar with. But such interpretation is no mechanical procedure carried out in accordance with, and in that sense guided by, rules or conventions formulated in advance and simply applied to the case. It involves skills, or strategies, which we all have. Our ability to understand one another as we do is part of, and ultimately not easily distinguishable from, our knowing our way around in the world generally. And there are no rules or directions for doing that. There are better and less good ways of doing it, depending on what is at stake, but there is no way of formalizing a set of procedures, or teaching a set of instructions, that would be guaranteed to churn out the right answer each time, any more than there is an algorithm for discovering anything else about the world.

I think it is Davidson's idea that what holds for the understanding of malapropisms, mistakes, and misuses of words, which is what I have been talking about so far, holds as well when we happen to share the language with the speaker, and the words we hear are just the words we expect to hear, and we assign them the meanings they are assigned by a theory of meaning for the language in question. Even then we are interpreting and understanding what a person is saying; we do not simply insert the utterance into a meaning-generating machine and read off the output. Even if we had such a theory of meaning, and so such a machine, and everything it said about the particular lan- 
guage in question was correct, it would not follow from the fact that it assigns a certain meaning to an expression in that language that someone using that expression on a particular occasion uses it with that meaning. That doesn't follow even if the person's only language is the language in question. Something more than, or something different from, what a theory of meaning for that language would tell us is needed in order for us to understand what anyone is saying when he uses the words that the theory of meaning tells us the meanings of.

This is the important point, or fact, that I think Davidson wants to insist on. It is a point, or a fact, which many people seem to resist, and so are led into great difficulty, or paradox. The point is that what we have just seen to be true of interpreting malapropisms and misuses - namely, that a theory of meaning for the language is not enough when the intended meaning differs from the meaning assigned by the theory - is also true of interpreting standard, non-deviant utterances, when the intended meaning is the same as what the theory of meaning says it is. Even then, in Davidson"s words, there is "no learnable common core of consistent behaviour, no shared grammar or rules, no portable interpreting machine set to grind out the meaning of an arbitrary utterance". 10

Philosophers who resist or deny that will concede that a theory of meaning does not suffice for the interpretation of speakers whose uses of words deviate from the standard uses that the theory describes. But they deny that it follows that a theory of meaning does not suffice when speakers' uses of words are in accord with the uses the theory describes. After all, any particular utterance can be deviant on a particular occasion, so the general theory will not be sufficient for interpretation when

10 Ibid., p. 173. 
that happens, but it is not possible for all or most uses of an expression in a natural language to deviate in meaning from what a correct general theory of meaning for that language assigns to it. Since the way expressions of the language are actually used is all there is for an empirical theory of meaning for that language to capture, repeated and widespread so-called "deviation" from the meanings assigned by the theory would simply mean that the theory in question is wrong. It would not accurately describe the way those expressions are in general used. Most speech in a given language has to be in accord with what a correct theory of meaning for that language says. So if we apply that correct theory of meaning to utterances in that language, we will be right most of the time.

This last point is certainly right. And perhaps from the fact that something more than a theory of meaning is required in deviant cases it does not strictly follow that something more is required in standard, non-deviant cases as well. But still, I think the conclusion is true; a theory of meaning alone does not suffice for interpreting speech, even in the normal case in which a single, widely-shared language is being used correctly.

That is because speaking, or communicating, involves saying something, which is a case of doing something, and no theory of meaning for a language can tell you what a person is going to do or how he is going to do it, and no such theory alone can tell you what a person is doing on a particular occasion, or how he is doing it. It can tell you what the words he utters mean, and so it can tell you, conditionally, what he would mean or what he would be saying if he were speaking literally or using his words with the meanings they standardly have in his language. But what a speaker is actually up to on any given occasion is something that a hearer has to recognize or figure out, 
even if he knows the speaker's language, or even if he has a theory of meaning for that language. I don't mean that it is difficult to recognize what our fellow human beings are doing, or that in the normal case it represents any kind of challenge at all. I mean only that a theory of meaning for a person's language does not alone tell us what the person is saying on any occasion.

That seems hard to deny. And perhaps no one would deny it. But if it is undeniable it is because a theory of meaning for a language is being understood as a theory the statements of which are true if the expressions of the language in question are in fact in general used in the ways those statements say they are. In that sense the theory describes a general practice; it is about what goes on in general. Whether a particular person's utterance on a particular occasion conforms to those general statements or not is always a further question. And that question cannot be answered by a general theory of meaning for the person's language.

As I said, that seems hard to deny. But many philosophers will object that a theory of meaning as we have been understanding it so far is too modest, or that a philosophical account of meaning and understanding should give us more. That is, many appear to aspire to an account of meaning that will tell us what someone means when he utters certain words. That is something we usually come to know when we hear someone speak, and many philosophers appear to think of that knowledge as something we derive from our knowledge of the language, or of the meanings of words, or of the meaning of something.

Michael Dummett, for instance, has long maintained that "a theory of meaning is a theory of understanding". One thing he has meant is that, as he put it, "what a theory of meaning has to give an account of is what it is that someone knows when he knows the language, that is, when he 
knows the meanings of the expressions and sentences of the language". ${ }^{11}$ Just as it stands, that seems like a reasonable demand. And I think, and I think Davidson thinks, that a correct theory of meaning as we have been understanding it so far could be said to do that. Competent speakers of English know the meanings of the (or most of the) expressions and sentences of English, and if a theory of meaning for English accurately reveals those meanings by showing how the meanings of some expressions are related to and built up out of the meanings of others in the systematic way that a recursive theory describes, then that is what competent speakers can be said to know about the meanings of those English expressions. They know what those expressions mean, and they know they are related in those ways. So the theory does give an account of what someone knows when he knows the language.

But Dummett thinks that a theory that does only that much would be too modest to provide what he calls a "philosophical understanding" of meaning. He thinks it would not explain communication and understanding because he thinks speakers' knowledge of their language is what enables them to speak and understand one another. As he more recently puts the point, "A speaker's employment of his language rests upon his knowledge of it; his knowledge of what the words and sentences of the language mean is an essential part of the explanation of his saying what he does." 12 Now being an "essential part" of the explanation of a speaker's saying what he does does not perhaps go beyond the more modest idea of a theory of meaning as we have been thinking of it so far. There might be other equally "essential" parts of the explanation

11 M. Dummett, "What Is a Theory of Meaning? (I)", in his The Seas of Language, Oxford University Press, Oxford, 1993, p. 3.

12 The Seas of Language, p. xi. 
of a speaker's saying what he does. But Dummett appears to be demanding more of a theory of meaning when he holds that a speaker's employment of his language "rests upon his knowledge of it". He thinks a person's knowledge or mastery of his language should explain his giving particular meanings to his utterances and should explain his understanding the meanings of the utterances of others. That is why he thinks a satisfactory theory of meaning for a language should do more than just tell us what competent speakers of that language in fact know.

This is what imposes more ambitious demands on a theory of meaning for a language than we have been supposing so far. It is not easy to see exactly what these additional demands are - or, once they are made clearer, whether they could ever be fulfilled. A satisfactory theory on this richer conception should also include an account of what having knowledge of the language "consists in" —or, as Dummett also puts it, it should explain how that knowledge of the language is "delivered" to the speaker. ${ }^{13}$ If his knowledge of the language is what enables a speaker to say things in that language and to understand the utterances of others, and if his speaking and understanding as he does "rests on" that knowledge, then the theory must explain (in Dummett's words) "how possession of the ... knowledge operates to guide, prompt, or control the speaker's utterances", or "how the knowledge is applied when the occasion for its application arises". 14 Particular applications of the knowledge - particular utterances in the language, or understandings of particular utterances of others - are to be shown to be drawn out of, or derived from, one's knowledge of the language. So any theory of meaning that captures the knowledge one has in knowing a language

13 Ibid.

14 Ibid. 
should account for that fact. A theory that simply stated how speakers of that language in general actually speak, or under what conditions the expressions they use are true - and in that sense what they know- would not do that.

I think Dummett's thought is that if to describe someone as knowing a language were simply to say that his speech instantiates and in that sense conforms to the statements of a correct theory of meaning for that language, then attributing such knowledge to a speaker would just be a way of describing his behaviour. As Crispin Wright, following Dummett, once put it, such a minimal ascription of knowledge would not "supply the needed contact of the theory with the ... speakers' actual performance" ${ }^{15}$ In talking of speakers' knowledge in only that modest sense "there is no real suggestion of [what Wright calls] an internalized 'programme'. All that such talk need involve is that speakers' practice fits a certain compendious description". ${ }^{16}$ And that is felt not to be enough. Dummett in a similar vein requires that we think of knowledge of the language as what he calls a "mechanism" 17 or a "piece of internal (mental) equipment"18 by which speakers are "guided" or "controlled" in saying what they say and in interpreting the utterances of others. That is what he thinks the philosopher interested in meaning and understanding should account for. If that is what mastery or knowledge of a language is, and if a theory of meaning for a language is a theory of what a speaker knows when he knows that language, then a theory of meaning should explain

15 Crispin Wright, "Rule-Following, Objectivity and the Theory of Meaning", in S.H. Holtzman and C.M. Leich (eds.), Wittgenstein: To Follow a Rule, Routledge and Kegan Paul, London, 1981, p. 110.

16 Ibid.

17 The Seas of Language, p. xii.

18 M. Dummett, "What Do I Know When I Know a Language?, in his The Seas of Language", p. 97. 
how the contents of that "piece of internal equipment" are "delivered" to a speaker to "guide, prompt, or control" his utterances and his interpretations of the utterances of others.

This might look like just a different conception of a theory of meaning for a language, or stronger requirements for what Dummett thinks of as a "philosophical understanding" of meaning. But for Dummett and others it is more than that. It is the basis of an objection to all theories of meaning expressed in terms only of truth —or perhaps I should say of truth understood non-epistemically.

Dummett thinks a theory of meaning for a person's language should explain the person's mastery of the language, and that "this explanation must embody an account of what it is to have the concepts expressible in the language". 19 And a theory of meaning in terms of truth or truth-conditions alone, he thinks, fails to do that. It will say such things as that in English the predicate '... is a bed' is true of an object if and only if that object is a bed, or that the sentence 'Snow is white' is true if and only if snow is white. But that is to make use of the very concepts that are said to be expressed by the words whose meanings or truth-conditions the theory states. That is something that Davidson right from the beginning has said is only to be expected from a truth-conditional theory of meaning. ${ }^{20}$ Only someone who knows what a bed is could learn from that explanation what the predicate '... is a bed' means, and only someone who knows what snow is, and knows what it is for something to be white, could grasp the meaning of 'Snow is white' from the fact that that T-sentence is derivable in the theory.

19 Ibid., p. 99.

${ }^{20}$ See, e.g., his "Semantics for Natural Languages", in his Inquiries Into Truth and Interpretation, p. 56. 
When the language under study is different from the language in which the theory of meaning is stated, a truth theory looks in a way more helpful. In that case, there could be a kind of explanation of a person's mastery of a language. Someone who speaks English might, theoretically at least, come to know Spanish by consulting a theory of meaning for Spanish that is expressed in English. In Spanish, he finds, '... es una cama' is true of an object if and only if that object is a bed, 'La nieve es blanca' is true if and only if snow is white, and so on. His mastery of Spanish would be explained by his knowledge of a theory of meaning for Spanish, but only because he already possesses the concepts that he is learning to express in Spanish. And his possession of those concepts is embodied in his prior mastery or knowledge of English. Obviously his mastery of English would not be explained in the same way by attributing to him knowledge of a truth theory of meaning for English expressed in English. Any such theory uses concepts to state the meanings or truth-conditions of expressions in the language, but it does not explain what it is to have those concepts. So having knowledge of such a theory would not be enough to explain a speaker's employment of his language.

Dummett accordingly demands of a theory of meaning that the knowledge of the meanings of expressions that it attributes to a speaker should explain a speaker's performance in speech and interpretation. It would have to be a knowledge of meanings that a speaker's application of his language to particular occasions in some sense "rests on". It would have to be knowledge that "operates to guide, prompt, or control the speaker's utterances". But in order to explain it in the right way, a theory of meaning would have to be an "account of the understanding of a language that makes no appeal to the prior grasp of the concepts that 
can be expressed in it". ${ }^{21}$ So it would have to attribute to a speaker an "internalized programme", or "mechanism", or "piece of internal (mental) equipment" which "delivers" appropriate particular utterances or interpretations of utterances to the speaker without requiring him to possess or grasp in advance the concepts that are expressed in the words he is being guided in the application or interpretation of.

This raises large and complex questions. I can deal briefly with some, and only sketchily with others. Does a theory of meaning for a language stated in terms of truth alone fail to meet these demands of Dummett's? As far as I can understand those demands, I think it does fail to meet them. Is that a fatal defect in a truth theory of meaning, or an objection to the enterprise of constructing such a theory? I cannot see that it is. A correct truth-conditional theory of meaning describes what speakers of a particular language know by stating or revealing the meanings of the expressions they understand and competently use. In speaking as they do, speakers exhibit the competence that the theory describes. But that competence is not something from which each exercise of it is somehow extracted or generated by application of the rules or principles of the theory. To have the competence or knowledge in question is simply to speak, or to have the ability to speak, in accord with the general practice that the theory describes.

Does that mean that a speaker's knowledge of his language cannot explain his performance in the language? Well, what needs to be explained in a particular context, and what it takes to explain it, seem to me highly variable. If I am travelling with a friend in Turkey and he is having a much better time than I am, I might ask myself

21 “What Do I Know When I Know a Language?", in The Seas of Language, p. 99. 
why. What explains his great success in interacting with all those Turks, or the ease with which he communicates with them, whereas I am getting nowhere, and no one is paying any attention to me? The explanation is that he knows Turkish. His knowledge of the language is what explains his performance, and my ignorance of it is what explains mine. But that does not mean that his successful performances are churned out of some reservoir or mechanism called "knowledge of Turkish", any more than mine are churned out of a reservoir or mechanism called "ignorance of Turkish".

The fact that it attributes no such mechanism is not an objection to, or a shortcoming of, a theory of meaning in terms of truth. It couldn't be. Having knowledge of the meanings of all the expressions in a language is not enough to determine what a speaker means in making a particular utterance. That is just the point Davidson insists on. There is no "portable interpreting machine set to grind out the meaning of any arbitrary utterance". If such a machine, or knowledge of a language so understood, were required for communication and understanding, there would be no such thing as communication and understanding. If competence or mastery of a language had to be understood in that way, there would be no such thing as competence or mastery of a language. In other words, "there is no such thing as a language, not if a language is anything like what many philosophers and linguists have supposed".

This raises deeply obscure questions about the source, the nature, and the reasonableness of Dummett's demands. I am very uncertain about this. What do Dummett and those who seek a more epistemically-oriented account of meaning really want? And why? They want a theory of meaning or understanding that would ascribe to speakers something that explains, in the sense of containing, generating, or guiding — and so giving meaning to - the particu- 
lar utterances they make. But whatever plays that role must be a body of knowledge: something that speakers know. But if a person knows something, he must understand the content of that knowledge; he must have or grasp the concepts used in expressing what he is said to know. That is precisely why Dummett thinks a truth-conditional theory of meaning could not explain a speaker's performance; to have the knowledge that such a theory attributes, a speaker would have to understand, and so already possess, the concepts used in the T-sentences that the theory states.

So what must be in the mind of a speaker that would explain his performance in the right way is something he knows and understands, but it must also genuinely guide or control him, so it cannot rely on or presuppose his possession of the very concepts in the expression of which it is guiding or controlling him. So it cannot guide him only in the way in which instructions in English could tell someone how to say things in Spanish. A theory of meaning of the sought-for kind is supposed to apply to a person's mastery of his first, or only, language. This makes it look as if it must attribute knowledge that instructs or guides a speaker in saying and understanding things in the very language in which it instructs or guides him. But no knowledge or information could guide or instruct a person in coming to possess the very information that is supposed to be guiding him in that way.

Dummett concedes, of course, that it cannot be demanded of a theory of meaning for a language that it should be capable of conveying "every concept expressed by a word in the language to one who does not possess it; some concepts must be taken as basic". ${ }^{22}$ And there will be others that "cannot by their nature be conveyed by means of a

22 The Seas of Language, p. viii. 
verbal explanation". ${ }^{23}$ But for the rest, a condition of adequacy for a theory of meaning for a language appears to be that it should convey to someone who does not know the language or possess most of the concepts expressible in it an understanding of the expressions of the language, and so possession of those concepts. This makes it look as if Dummett's demands could be met only by a theory or body of information that tells a person how to speak, or what words to apply on what occasions, and it must do so without presupposing that he has any prior knowledge or understanding of what he would be doing or saying by using those words in those ways on those occasions.

This is perhaps what seems to recommend rejection of a truth-conditional theory of meaning in favour of a conception "according to which the meaning is to be explained in terms of what is taken as justifying an utterance", ${ }^{24}$ and why "assertibility conditions" are thought to be essential to an account of the meanings of sentences. The idea appears to be that to know the meaning of a sentence is to be able to recognize the conditions in which to use it or apply it. But if that knowledge of those "assertibility conditions" does not make use of or presuppose a grasp of the concepts that would be expressed in the application or utterance of that sentence under those conditions, the most it could tell a speaker is that under those recognizable conditions the application or assertive use of the sentence would be justified. But in uttering a sentence a speaker will be making an assertion only if knows what that sentence means, or what assertion he is making. And his knowledge only of the conditions under which he can justifiably utter

${ }^{23}$ Ibid.

${ }^{24}$ M. Dummett, "Can Analytical Philosophy Be Systematic, and Ought It To Be?", in his Truth and Others Enigmas, Harvard University Press, Cambridge, Mass., p 452. 
a certain sentence assertively does not tell him that. That is something that a truth-conditional theory of meaning for a language could tell someone: what assertion he would be making if he uttered a certain sentence and meant by it what it means in the language. But it could tell that only to someone who already understood and so possessed the concepts expressed in the assertion. For a person who lacks those concepts and that understanding, the sentence would be no more than a string of words or marks. Something that told him when he would be justified in uttering those words or writing those marks assertively would not tell him what assertion he would be making if he did that. And it would not guide him in making any particular assertion either.

I confess bewilderment about the idea of meaning as embodied in the so-called "assertibility conditions" of an expression, and about how even a theory of meaning that did make use of that notion could do what Dummett appears to demand.

In Wittgenstein's later treatment of such notions as meaning and understanding there is a sustained attack on the idea of a person's knowledge or understanding of meaning as a state or mechanism from which his acts or performances spring as from a reservoir ${ }^{25}$ and which generates or guides, and in that sense explains, particular manifestations of that knowledge or understanding. He thinks there is what he is inclined to call "a curious superstition" or "a kind of general disease of thinking which always looks for (and finds)" such a mechanism. ${ }^{26}$ But no equipment, no item or formula or expression in the mind - or anywhere else - could guide us or instruct us in its applications unless we understood it or it expressed something we know or

25 L. Wittgenstein, The Blue and Brown Books, Blackwell, Oxford, 1958, p. 143.

26 Ibid. 
believe. It could not show or tell us what to do if it meant nothing to us. So one thing it could not tell us is how to understand or interpret it. There must therefore be a way of interpreting or understanding something which is not a matter of following instructions or being guided in one's interpretation or understanding. ${ }^{27}$ This is just what makes it look as if Dummett's demands could never be fulfilled. To understand something is to be capable of manifesting that understanding; it is not necessarily to grasp or understand something that generates or guides those manifestations.

This, I believe, is what Wittgenstein is getting at when he says that when we have attained "greater clarity about the concepts of understanding, meaning, and thinking" it will then become clear what can lead us — and did lead him, he says - "to think that if anyone utters a sentence and means or understands it he is operating a calculus according to definite rules". ${ }^{28}$ The point is not that such a person is operating a calculus according to "indefinite" rules instead. The point is that he is not operating a calculus or mechanism at all. This is fully in accord with Davidson's verdict that "there is no portable interpreting machine set to grind out the meaning of any arbitrary utterance".

But the demand for a mental mechanism or reservoir remains. In a curious twist, Crispin Wright found in the later work of Wittgenstein what he thinks of as "a number of prima facie challenges to the idea" of a theory of meaning for a language expressed in terms of truth-conditions - or perhaps a theory expressed in any terms at all. ${ }^{29} \mathrm{In}$

27 See, e.g., L. Wittgenstein, Philosophical Investigations, Blackwell, Oxford, 1953, §201.

28 Ibid., $\$ 81$.

29 "Rule-Following, Objectivity and the Theory of Meaning", p. 112. 
fact, he perceived "a very fundamental tension" between what Wittgenstein says about meaning and understanding and "thinking of language as amenable even to description by the sort of theory envisaged" by Davidson. ${ }^{30}$ But this alleged challenge or tension arises only from Crispin Wright's and Dummett's requirement that any such theory of meaning must attribute to speakers of the language some knowledge the possession of which will "explain the potentially infinitary character of mastery of ... the natural language". ${ }^{31}$ A theory that captures that mastery must explain a speaker's knowledge or recognition of the meanings of novel sentences in his language, and not simply describe that mastery and attribute it to speakers.

Wittgenstein does indeed oppose that conception of a mental mechanism that generates and in that sense explains particular instances or applications of one's mastery. But that does not threaten or challenge the idea of a theory of meaning for a natural language that does not require or attribute any such mechanism or explanation. Even less does it threaten the views of someone who denies that there is any such mechanism.

In a further twist, Saul Kripke has found in Wittgenstein an argument for the paradoxical or sceptical conclusion that there is no such thing as a person's meaning one thing rather than another by any utterance that he makes. What Wittgenstein does argue is that there could be no item the mere presence of which in the mind or anywhere else determines that it has a certain meaning or determines that I mean such and such when I utter a sound with that thing present in my mind. That will imply that nobody ever means one thing rather than another when he utters something only if one further assumption is made.

30 Ibid., p. 114.
31 Ibid., p. 111. 
Kripke sometimes appears to make that assumption, or to be tempted by it, although he quite rightly does not claim to find it in Wittgenstein.

He says he sometimes has "something of an eerie feeling. Even now as I write, [he says] I feel confident that there is something in my mind - the meaning I attach to the 'plus' sign - that instructs me what I ought to do in all future cases. I do not predict what I will do ... but instruct myself what I ought to do to conform to the meaning .... But when I concentrate on what is now in my mind, what instructions can be found there? ... What can there be in my mind that I make use of when I act in the future? It seems that the entire idea of meaning vanishes into thin air." 32 Kripke says Wittgenstein accepts this conclusion; it is part of "a picture of language based, not on truth conditions, but on assertability conditions or justification conditions". ${ }^{33}$ There is no fact as to whether Jones means addition by the word 'plus', but the use and therefore the meanings of sentences like "Jones means addition by the word "plus" " can nonetheless be explained in terms of their "assertibility conditions". They in turn are to be understood only as the conditions of "acceptance" or "rejection" of Jones as a member of the linguistic community, not as conditions under which someone who uttered such a sentence would say something true about what Jones means. The sceptical conclusion is that there is nothing that is true or false as to what Jones means.

But when Kripke says that meaning vanishes, or that no one ever means anything, we should keep reading, just as we had to keep reading when Davidson said there is no such thing as a language. It is the very idea of something

${ }^{32}$ S. Kripke, Wittgenstein on Rules and Private Language, Harvard University Press, Cambridge, Mass., 1982, pp. 21-22.

33 Ibid., p. 74. 
in the mind that instructs or guides a person's meaning or understanding what he does that Wittgenstein exposes as a widespread philosophical illusion. But without that idea, the sceptical or paradoxical conclusion cannot be reached in the way Kripke reaches it. So what Kripke actually establishes in the name of Wittgenstein is equivalent to what can be put in a way that brings it closer to the text from Davidson with which I began: "there is no such thing as a person's meaning something, not if meaning is anything like what many philosophers have supposed".

Recibido: 21 de enero de 1998 